\title{
Saphenous Artery Perforator/Propeller Flap in the Reconstruction of Perigenual Soft Tissue Defects
}

\author{
T. M. Balakrishnan ${ }^{1, \odot}$ Aishwarya Vadakencherry Lakshmi Narayanan ${ }^{1} \quad$ J. Jaganmohan ${ }^{1}$ \\ ${ }^{1}$ Department of Plastic and Faciomaxillary Surgery, Madras Medical \\ College, Chennai, Tamil Nadu, India

\begin{abstract}
Address for correspondence T. M. Balakrishnan, MBBS, MS (Gen surg), FRCS (E), DNB (Gen surg), MCH (Plastic surg), DNB (Plastic surg), Old no 15, new no 10, Thiruvalluvar street, Rangarajapuram, Kodambakkam, Chennai 600024, Tamil Nadu, India (e-mail: thalaiviri.b@gmail.com).
\end{abstract}

Indian J Plast Surg 2019;52:330-336

\begin{abstract}
Keywords

- perigenual soft tissue defects

- saphenous artery perforator propeller flap

- saphenous vessel

- soft tissue defects of the knee

Introduction In this article, we investigate the saphenous artery perforator propeller flap for the reconstruction of perigenual defects. We describe the anatomy of the saphenous artery and the method of raising a perforator propeller flap based on our study and early clinical experience.

Aim To assess the effectiveness of the saphenous artery perforator propeller flap in the reconstruction of perigenual defects.

Materials and Methods A preliminary cadaver dissection and injection study was conducted to discern the anatomical details of the perforator system of the saphenous vessel in 35 cadaveric specimens in 18 fresh cadavers. From March 2016 to March 2018, 16 clinical cases ( 5 females and 11 males, in the average age group of 33.5 years) with perigenual defects were reconstructed with saphenous artery perforator propeller flap. They were followed up for an average period of 12.5 months.

Results Cadaver study established anterior sartorial perforators as the dominant system of the saphenous vessel and brought to the forefront the type 2 blood supply of the saphenous nerve. All patients had well-settled flaps at the end of the follow-up period, with good return of knee function.

Conclusion Saphenous artery perforator propeller flap is a viable option for the reconstruction of defects around the knee joint.

Level of Evidence Type V, therapeutic study.
\end{abstract}

\section{Introduction}

Perigenual soft tissue defects are a challenging exercise as there is an unpropitious interaction between three factors: (1) $60 \%$ of the knee joint circumference is subcutaneous (making it vulnerable to exposure even with moderate violence injuries), (2) single major neurovascular bundle is in close proximity to the posterior aspect of the knee joint (rendering the popliteal artery more susceptible to injury in subluxation/ dislocation injuries of the knee joint and rendering all local perforator flaps unreliable), and (3) there is paucity of loose skin around the knee joint (making primary closure and local flaps reconstruction a difficult task). Reconstruction of perigenual soft tissue defects should pave the way for regaining

received

May 8, 2019

accepted after revision

October 4, 2019

published online

December 23, 2019 the preinjury functional level and maintaining the local aesthesis. The essential characteristics of the flaps to fully achieve these two goals are thin pliable nature with good color/ texture match and robust blood supply to heal the exposed bones and joint. To a variable extent, all these goals are attainable by various methods of reconstruction using local flaps to free flaps. An advanced understanding of the skin blood supply and its physiology has led to the birth of the perforator propeller flaps. Wei and Mardini, ${ }^{1}$ Mardini et al, ${ }^{2}$ and Wallace et $\mathrm{al}^{3}$ described the freestyle free and pedicled perforator flaps. "Any area of the body where there is audible Doppler signal that becomes the potential area of tailored flap that exactly suits need of recipient site in terms of color, texture, pliability and thickness " a concept came into being recently. ${ }^{4,5}$

(C)2019 Association of Plastic

License terms

Surgeons of India
DOI https://doi.org/

$10.1055 / \mathrm{s}-0039-3400354$ ISSN 0970-0358. 
Saphenous artery perforator propeller (SAPP) flap for the reconstruction of perigenual soft tissue defects is one such flap explored by the author in this article. Pedicled and free saphenous artery fasciocutaneous flaps, ${ }^{6-8}$ saphenous posteromedial cutaneous island thigh flaps, saphenous superomedial cutaneous island leg flaps, saphenous neurovenofasciocutaneous flaps, ${ }^{9,10}$ and reverse saphenous flaps ${ }^{11}$ are already well described in the literature. For the first time, clinical application of the pedicled SAPP flap that preserves the saphenous nerve, the great saphenous vein, and the saphenous vessels at the donor site is investigated by the author in this study.

\section{Aim}

The aim of this study is to assess the effectiveness of SAPP flap in the reconstruction of perigenual defects.

\section{Materials and Methods}

Institutional ethical committee approval was obtained prior to the cadaver and clinical study.

\section{Cadaver Study}

A preliminary cadaver dissection and injection study was conducted with an aim to discern the anatomical details of the perforator system of the saphenous vessel in 35 adult cadaveric specimens in 18 fresh cadavers (20 males and 15 females). Those with an injured thigh were excluded. For dye injection study, initially, the dilute formalin was injected to check for the rent in the proximal femoral vessel walls, which, if present, was sutured with fine silk. Then the formalin was milked and mopped out with woven cotton gauze. The India ink was injected in a retrograde manner through the femoral veins with little pressure following which diluted red lead oxide solution was injected into the femoral arteries. The specimens were frozen for 24 hours, and dissection was performed later. A single incision was placed on the lower third of the thigh close to the midline and then carried down to the medial side of the patella and the upper two-thirds of the medial side of the leg anterior to the saphenous nerve surface anatomy. Dissection in the suprafascial/subfascial plane to locate all the perforators from the saphenous vessels was performed ( $\boldsymbol{- \text { Fig. }} \mathbf{1}$ ). Then the saphenous vessels accompanying the saphenous nerve were followed distally and proximally. The pattern of origin of perforators from the source vessel, as well as their course, number, size, and location with respect to the knee joint line were noted. Magnifying loupes, scales, and calipers were used during the study.

\section{Clinical Study}

From March 2016 to March 2018, 16 cases (5 females and 11 males in the average age group of 33.5 years) of perigenual defects were reconstructed with SAPP flap. The etiology of soft tissue perigenual defects are posttraumatic $(n=11)$, postinfective $(n=2)$, postexcisional $(n=1)$, and postburn $(n=2)$. This is a prospective cohort study.

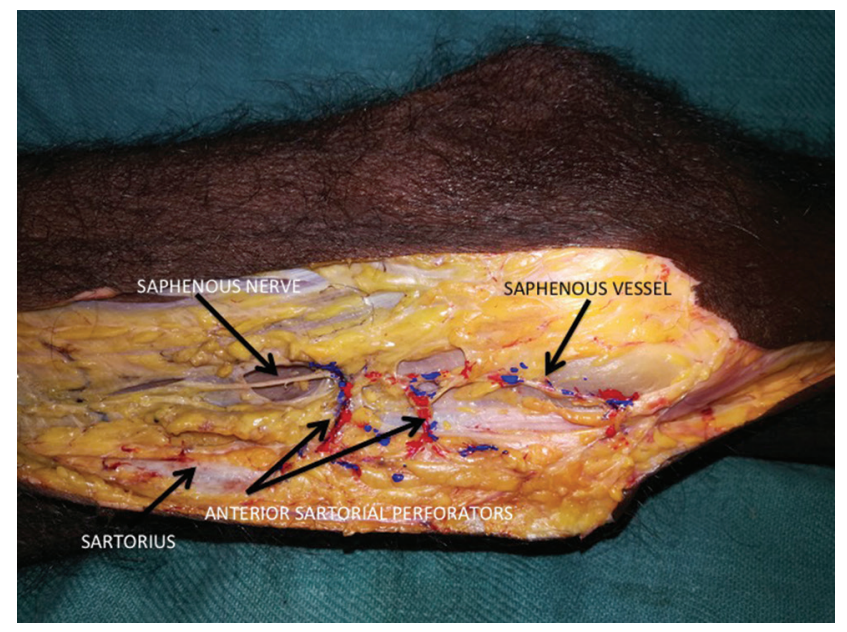

Fig. 1 Left lower medial thigh dissection showing saphenous anterior sartorial perforator dominance and the dominant saphenous vessel running along the saphenous nerve.

\section{Inclusion Criteria}

The study included patients with perigenual soft tissue defects and those with unviolated skin territory in the lower medial third thigh.

\section{Exclusion Criteria}

Patients with the following comorbid illnesses were excluded: (1) diabetes mellitus, (2) collagen vascular diseases, (3) smoking or nicotine consumption in any form, (4) vasculitis, (5) uncontrolled hypertension with cardiovascular instability, (6) immunocompromised, (7) ulcers due to vascular insufficiency, (8) flaps harvested on more than one perforator (as keystone flap) and V-Y advancement used as the primary movement of flap, (9) extensive degloving injuries and crush injuries, and (10) cases with popliteal artery reconstructed.

\section{Surgical Technique}

In all cases, a line is drawn from the anterior superior iliac spine to the adductor tubercle. Using a handheld 10-Mhz Doppler device, the perforators are marked just anterior and posterior to this line in the lower one-fourth. After excising the primary perigenual defect, a pattern is constructed with dimensional allowance for primary contraction of the flap and transferred with its axiality parallel to the long axis of the thigh and adjacent to the defect. A trilobed provisional flap is marked if the primary movement of the flap is less than 180 degrees. It is planned in such a way that a large paddle covered the primary defect and other two small paddles covered the secondary defects, with the additional advantage of reducing tension on the pedicle. The provisional pivot point is placed on the nearest best acoustic signaling perforator. Otherwise, a bilobed perforator propeller flap is planned if the primary rotation about pivot is 180 degrees. The dissection is always started with an anterior nondelineating incision (as our cadaver study and clinical study experience showed anterior sartorial perforators of the adductor canal segment of the saphenous vessel as dominant), and 
the subfascial dissection is performed till the perforators are encountered anterior to the sartorius muscle. Most of the time, more than two perforators are encountered. One that is nearest to the defect with good size and pulsatility is chosen. A liberal 2\% lignocaine irrigation is commonly used by the author during the skeletonization of the pedicle. A periperforator dissection is performed through the sartorius muscle and subsartorial fascia until approximately $2 \mathrm{~cm}$ of the pedicle is available for allowing the gracious turn of the pedicle without any occurrence of critical twist and kinking. Under magnification, all the fascial strands are removed from the skeletonized perforator pedicle that is commonly responsible for venous congestion of the flap. In all cases, the saphenous nerve, the main saphenous vessels, and the great saphenous vein are spared, and flaps are harvested on the single best perforator. Then the whole flap is raised after completing the delineating incision. After interpolation, the flap is given inset, and in those cases in which the transverse dimension of the resultant secondary defect is less than $8 \mathrm{~cm}$, it is closed primarily. If it is exceeding that dimension, split-thickness skin graft is used for the cover of the secondary defects.

\section{Postoperative Follow-Up}

A postoperative posterior popliteal fossa offloading plaster slab is used for a 2-week period, with mild limb elevation. Passive stretching exercises are started after 14 days and continued for another 2 weeks until active mobilization. All cases are followed up at 3, 6, 9, 12, and 15 months of interval following the discharge. They are followed for an average period of 12.5 months. At every contact point, the scars, local aesthesis, and functional recovery are assessed.

\section{Case 1}

A 42-year-old male presented with posttraumatic hemarthrosis and peripatellar soft tissue defect (measuring $9.5 \times 12 \mathrm{~cm}$ ) communicating with the knee joint through the suprapatellar bursa (-Fig. 2). After excision of the wound, a trilobed saphenous vessel perforator propeller flap was constructed with the preservation of the saphenous nerve, the saphenous vessel, and the great saphenous vein and transferred

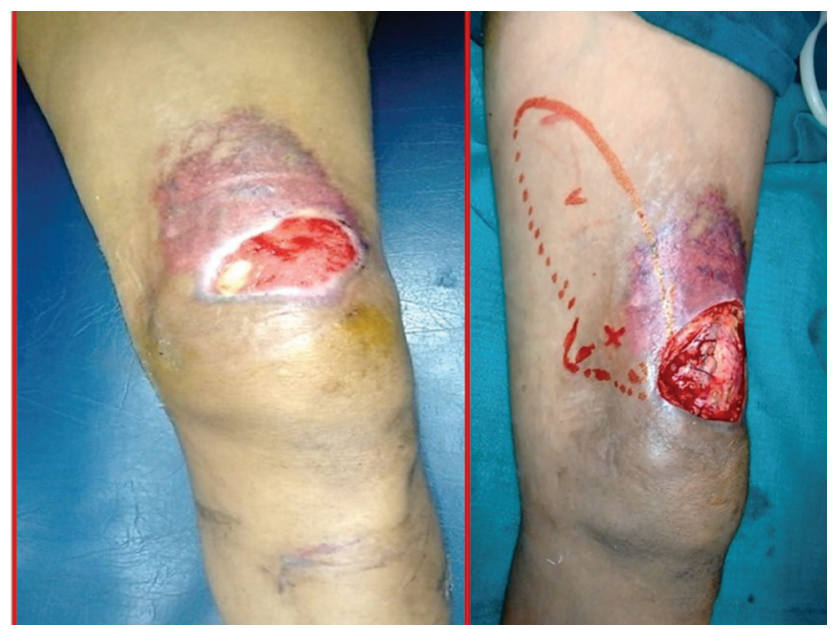

Fig. 2 Case 1: preoperative picture. to the defect (-Fig. 3). The flap is harvested on the anterior sartorial perforator. Secondary residual raw area is the skin grafted. The flap and reconstructed site healed well. Patient was followed up for 14 months. He developed normal range of knee movements and normal gait at 12 months follow-up (-Fig. 4).

\section{Case 2}

A 22-year-old male patient presented with unstable raw area on the medial aspect of knee surrounded by scar following a thermal burn. After excision of the defect, a saphenous vessel perforator propeller flap based on the anterior sartorius single best perforator flap (measuring $6 \times 7 \mathrm{~cm}$ ) was transferred to the defect ( $\mathbf{- F i g}$. 5). The patient was followed up for 12 months. He had a well-settled flap and was pain-free, with full range of movement in the knee joint (-Fig. 5).

\section{Case 3}

A 52-year-old male sustained degloving injury to the anterior aspect of the left knee with fracture femur in a road accident (-Fig. 6). Following debridement, $20 \times 11 \mathrm{~cm}$ of SAPP flap was harvested based on the anterior sartorial perforator ( $\mathbf{- F i g s .} 6$ and $\mathbf{7}$ ), preserving the saphenous nerve, the saphenous vessel, and the great saphenous vein. The secondary defect was covered with a medium-thickness split-skin

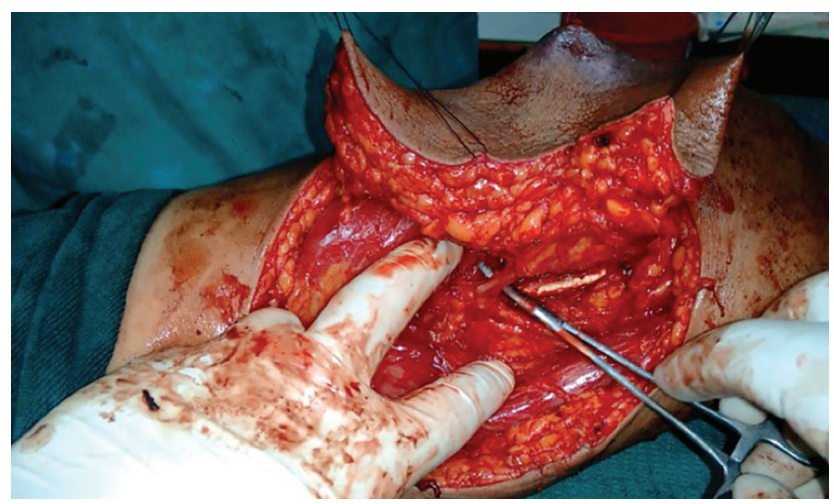

Fig. 3 Case 1: intraoperative picture showing the saphenous vessel perforator skeletonization and the preservation of the saphenous nerve.

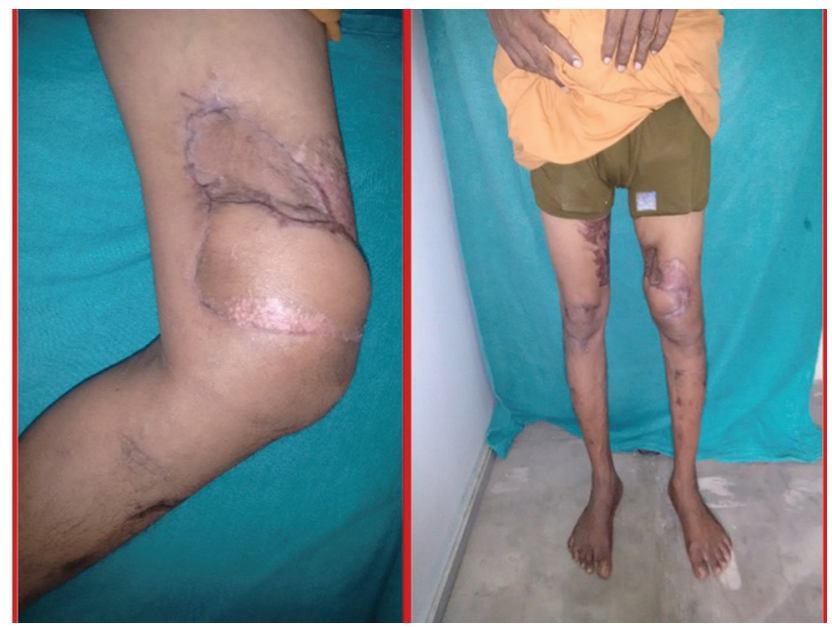

Fig. 4 Case 1: 1-year follow-up with good knee movement. 


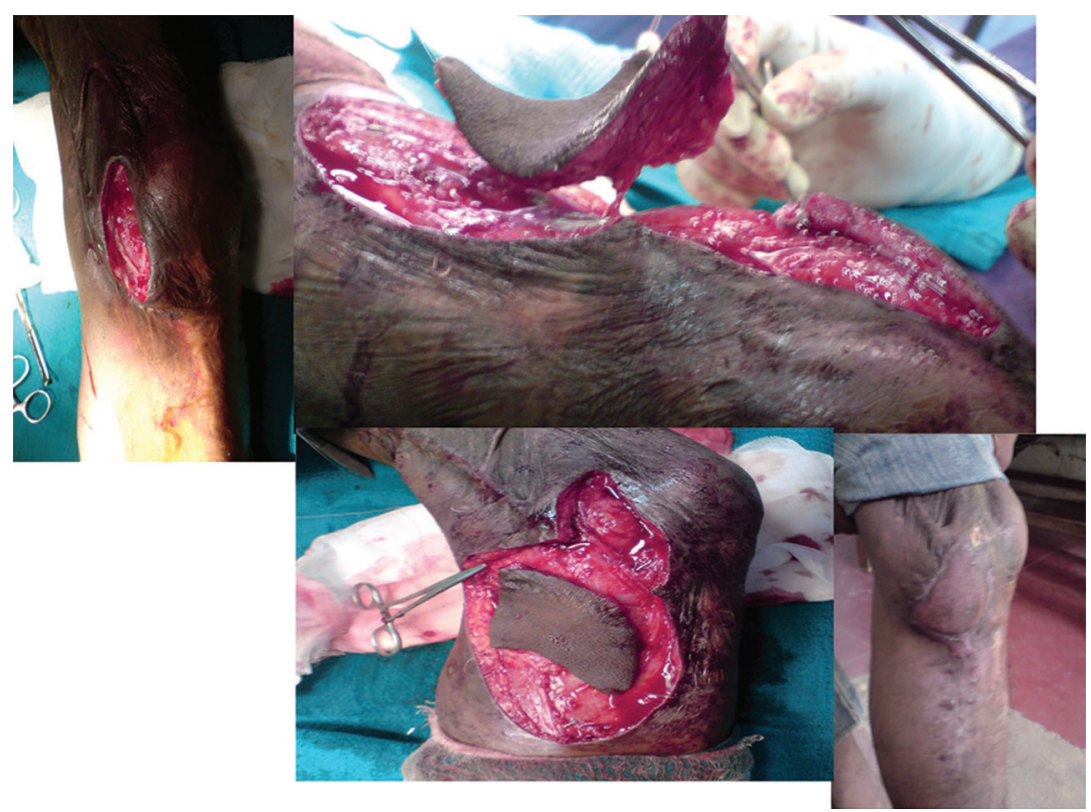

Fig. 5 Case 2: preoperative and late postoperative picture of unstable raw area treated with a saphenous flap.

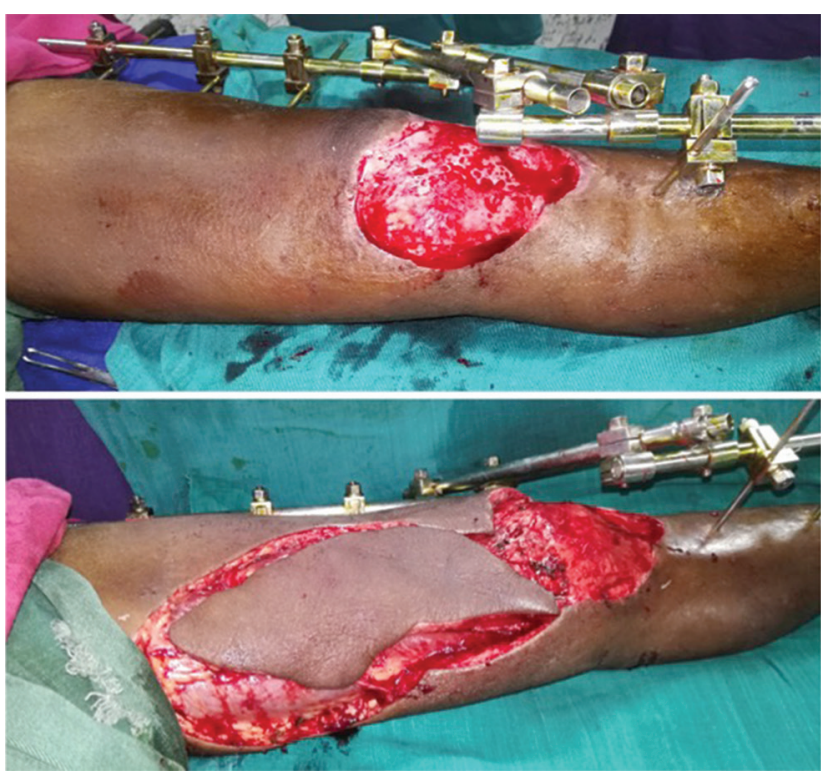

Fig. 6 Top: postdebridement defect on the anterior aspect of the left knee. Bottom: saphenous artery perforator propeller flap measuring $22 \times 11 \mathrm{~cm}$.

graft ( - Fig. 8). The patient developed $3 \mathrm{~mm}$ of superficial epidermolysis that healed well by secondary intention. He underwent a secondary internal fixation of the femur later. At a follow-up of 14 months, he had a well-settled flap with a good range of knee movements.

\section{Results of Cadaveric Study}

It was found in our study that the saphenous nerve received the single dominant saphenous vessel supply, which always originated from the descending geniculate vessels. Saphenous vessels originated as a second branch (as one artery and

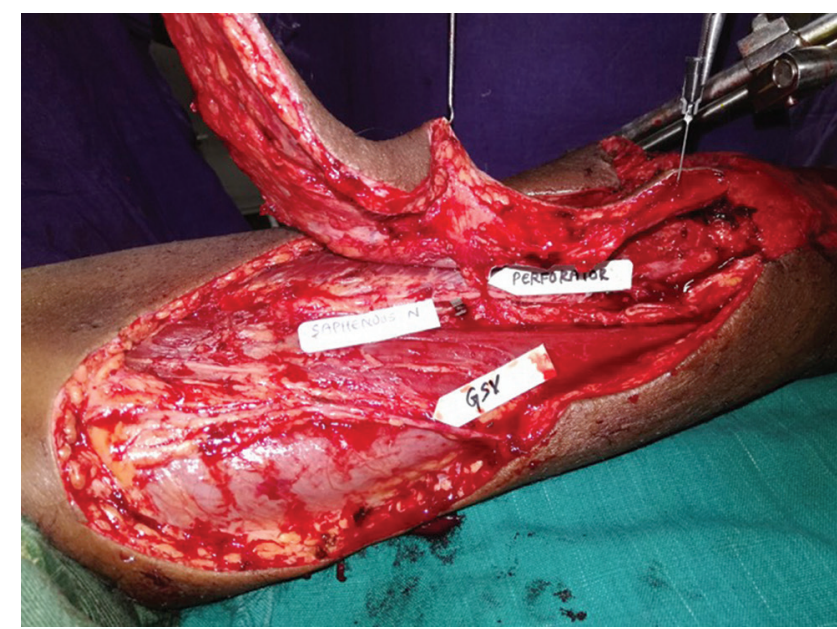

Fig. 7 Intraoperative picture of the saphenous artery perforator propeller flap.

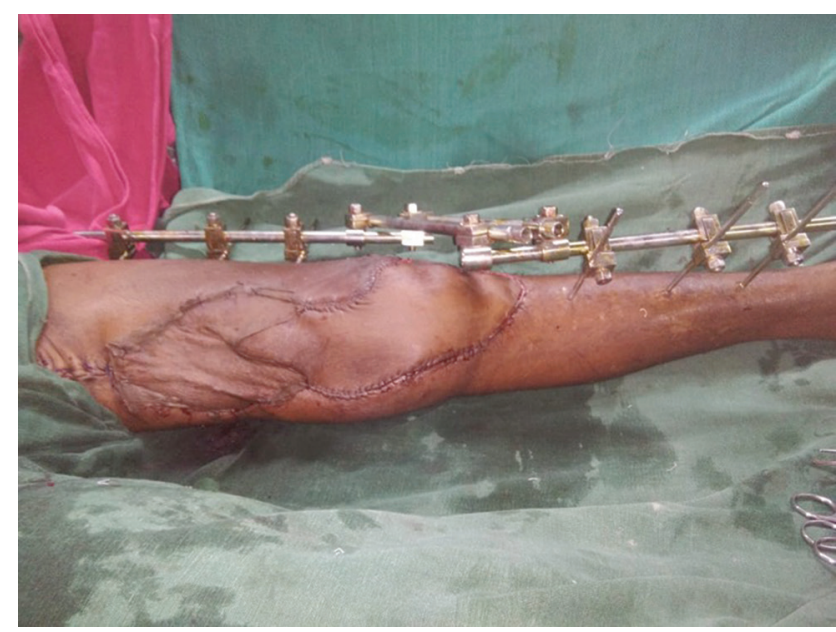

Fig. 8 Postoperative picture of the saphenous artery perforator propeller flap. 
two venae comitantes) from the descending geniculate vessels within the adductor canal in all the specimens. Its origin was in an average $11 \mathrm{~cm}$ proximal from the knee joint line and $2.5 \mathrm{~cm}$ from the origin of the descending geniculate vessels. The average dimension of the saphenous vessel at its origin was $1.75 \mathrm{~mm}$. It ran initially $2 \mathrm{~cm}$ on the posterior aspect of the saphenous nerve within the adductor canal. Then it ran on the nerve on average $10.5 \mathrm{~cm}$ from the knee joint line. In all specimens, they emerged with the saphenous nerve (continued as vasa nervorum and therefore the perforators can be rightly named as neurocutaneous perforators) just distal to the knee joint line in front of the gracilis tendon and through the posterior third of the sartorius tendon. Therefore, it could be described as having two segments. The first segment is the adductor canal segment $(10 \mathrm{~cm}$ in length on average) that gave rise to 3.5 number of perforators along the anterior border of the sartorius muscle, with an average size of $1.1 \mathrm{~mm}$ at its origin. The last perforator of this group was $2.5 \mathrm{~cm}$ proximal to the knee joint line. On average, two perforators originated from the posterior sartorial border with an average dimension of $1.2 \mathrm{~mm}$. The second segment is the distal segment that had 2.5 number of perforators, with the average size being $1.1 \mathrm{~mm}$. The last neurocutaneous perforator was situated on average $3.5 \mathrm{~cm}$ distal to the knee joint line. Therefore, in all specimens, anterior sartorial perforators were found to be dominant. There were no side variations. As per the classification by Breidenbach and Terzis, ${ }^{12}$, in all specimens, the saphenous nerve received the single dominant blood supply from the saphenous vessels that was type 2 blood supply. In all specimens, it was making anastomosis with upper medial geniculate artery (posterior to medial femoral condyle), and in $50 \%$ of the specimens, infragenicular segment was anastomosing with the perforator from the posterior tibial vessels.

\section{Results of Clinical Study}

The average size of the flap was $113.5 \mathrm{~cm} .{ }^{2}$ The average size of the single best perforator was $1.5 \mathrm{~mm}$. Age of these patients ranged from 17 to 60 years (-Table $\mathbf{1}$ ). There was no complete

Table 1 Demographic data of the patients

\begin{tabular}{|c|c|c|c|c|}
\hline $\begin{array}{l}\text { Case } \\
\text { number }\end{array}$ & $\begin{array}{l}\text { Age/ } \\
\text { sex }\end{array}$ & $\begin{array}{l}\text { Etiology and pathology and location of perigenual } \\
\text { defects }\end{array}$ & $\begin{array}{l}\text { Size of the flap }(\mathrm{cm}) / \\
\text { size of the SBP at the } \\
\text { subfascial level }(\mathrm{mm})\end{array}$ & $\begin{array}{l}\text { Complications/ } \\
\text { remarks }\end{array}$ \\
\hline 1 & $42 / \mathrm{M}$ & $\begin{array}{l}\text { PT: peripatellar region and hemarthrosis with suprapatellar } \\
\text { bursa communication exterior }\end{array}$ & $9.5 \times 12 / 1.5$ & Nil \\
\hline 2 & $22 / \mathrm{M}$ & $\begin{array}{l}\text { PB: unstable scar on the posteromedial knee region soft } \\
\text { tissue defect }\end{array}$ & $6 \times 7 / 1$ & Nil \\
\hline 3 & $52 / \mathrm{M}$ & PT: anterior knee and pretibial region soft tissue defect & $20 \times 11 / 1.5$ & $\begin{array}{l}\text { 3-mm superficial } \\
\text { epidermolysis at tip/ } \\
\text { healed well by second- } \\
\text { ary intention }\end{array}$ \\
\hline 4 & $60 / F$ & $\begin{array}{l}\text { PT: medial femoral condylar fracture and hemarthrosis/an- } \\
\text { teromedial knee region }\end{array}$ & $10 \times 17 / 1.5$ & Nil \\
\hline 5 & $26 / \mathrm{M}$ & PI: medial knee region & $4 \times 7 / 1.5$ & $\mathrm{Nil}$ \\
\hline 6 & $30 / \mathrm{M}$ & $\begin{array}{l}\text { PT: hardware exposure following superocondylar fracture } \\
\text { femur-medial knee region }\end{array}$ & $9 \times 6.5 / 1.5$ & Nil \\
\hline 7 & $36 / \mathrm{M}$ & PB: unstable scar anteromedial knee region & $9.5 \times 10 / 1.5$ & Nil \\
\hline 8 & $51 / \mathrm{M}$ & $\begin{array}{l}\text { PT: tibial plateau fracture with residual raw area following } \\
\text { gastrocnemius transposition on the anterior knee region }\end{array}$ & $6.5 \times 9 / 2.5$ & Nil \\
\hline 9 & $29 / \mathrm{M}$ & $\begin{array}{l}\text { PT: medial condylar fracture with raw area on the medial } \\
\text { knee region }\end{array}$ & $6 \times 9 / 1$ & \\
\hline 10 & $44 / F$ & $\begin{array}{l}\text { PE: medial knee region exposing joint line following aneu- } \\
\text { rysmal cyst excision }\end{array}$ & $10.5 \times 17 / 1.5$ & Nil \\
\hline 11 & $23 / \mathrm{M}$ & PT: patella fracture exposed the patellar region & $12 \times 19 / 2$ & Nil \\
\hline 12 & $36 / F$ & $\begin{array}{l}\text { PT: medial femoral condylar fracture exposing the antero- } \\
\text { medial knee region }\end{array}$ & $19 \times 7.5 / 1$ & Nil \\
\hline 13 & $55 / \mathrm{M}$ & PT: tibial plateau fracture exposed the anteromedial region & $7 \times 4 / 1.5$ & Nil \\
\hline 14 & $26 / F$ & $\begin{array}{l}\text { PT: patella fracture hemarthrosis suprapatellar region } \\
\text { exposed }\end{array}$ & $12 \times 19 / 1.5$ & Nil \\
\hline 15 & $43 / \mathrm{F}$ & PT: patellar fracture exposed the anteromedial knee region & $8 \times 12 / 1.5$ & $\begin{array}{l}\text { 4-mm tip necrosis with } \\
\text { infection healed by } \\
\text { secondary intention } \\
\text { after debridement }\end{array}$ \\
\hline 16 & $60 / M$ & PI: postnecrotizing fasciitis medial knee joint line & $10 \times 7.5 / 1.5$ & Nil \\
\hline
\end{tabular}

Abbreviations: F, female; M, male; PB, postburn; PE, postexcisional; PI, postinfective; PT, posttraumatic. 
loss of flap in our study. One patient had partial superficial epidermolysis, and dermal healing followed uneventfully. Another patient had 4-mm distal tip necrosis, which healed well with secondary intention. Incidence of complications in our series was $12.5 \%$. No other complication was encountered. There was an aesthetically acceptable scar at donor site in all cases. No other secondary procedures were needed (like flap thinning or correction of the standing cone). All patients assumed pain-free walking at an average follow-up of 12 months. The great saphenous vein and the saphenous nerve were preserved in all cases when they were intact. Even the saphenous artery was preserved at the donor site in all cases. Ten cases required skin grafting for the secondary raw areas. Remaining secondary defects were closed primarily. The average duration of surgery was 1 hour and 30 minutes.

All patients have well-settled flaps, and at the end of the follow-up period, they had good return of knee function and

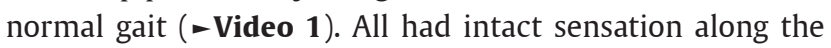
saphenous nerve distribution.

\section{Discussion}

Several cadaver studies ${ }^{13-15}$ have been conducted on saphenous vessels and its source vessels, the descending geniculate vessels. None of these studies concentrated on the origin, course, and perforators of the saphenous vessels. The vastus medialis perforators are also included in a study, ${ }^{15}$ which mar the clarity of anatomy of the saphenous vessel system. This study is directed toward the saphenous vessel system only. Our cadaver study establishes two important findings. First, the anterior sartorial perforators are dominant and large in size and numbers. Second, the saphenous nerve received the single dominant blood supply from the saphenous vessels that was type 2 blood supply. Cormack et $\mathrm{al}^{16}$ in their textbook mentioned the possible dominance of posterior sartorial perforators of the saphenous system. They also mentioned that "there are instances recorded in the anatomical literature where a well-developed saphenous artery reached the foot," but we did not find one such thing in our dissection. Our cadaver dissection has guided us on two things: (1) anterior nondelineating as first incision as we find the anterior sartorial perforators are uniformly dominant and (2) periperforator dissection through the septum and the sartorius muscle to preserve the great saphenous vein, the saphenous nerve, and the saphenous vessels.

With the advent of perforator propeller flaps, main source vessels, cutaneous nerves, and muscles are spared, leading to no or minimal donor-site morbidity. ${ }^{17}$ In all cases, the saphenous nerve, the main saphenous vessels, and the great saphenous vein are spared, and flaps are harvested on the single best perforator. This saphenous vessel axis, as established by our cadaver study, has potential of providing flaps in various avatars such as perforator-based keystone flaps, ${ }^{18}$ freestyle pedicled flaps, and free flaps, and also in various tissue composition such as adipofascial, cutaneous, osteocutaneous, and musculocutaneous composition. The SAPP flap is microvascular surgery minus microvascular anastomosis. They have homogenized robust vascular supply like any single best perforator based flap. ${ }^{19,20}$ When the gastrocnemius muscle ${ }^{21-26}$ and other locoregional fasciocutaneous flaps $^{27,28}$ for the reconstruction of perigenual defects become a difficult choice due to their small size, hard reach, or the secondary defects that may expose the subcutaneous prominences of the knee joint, the SAPP flaps become the ideal choice for aesthetic reconstruction. The maximum dimension of the SAPP flap used successfully by the author (case 3 ) is $20 \times 11 \mathrm{~cm}$. But the baffling question of "what is the safe dimension of the flap that can be harvested on the single best perforator?" remains to be answered by large-scale studies. ${ }^{29}$ Only one research work closely relating to this study is that by Winkel et al, ${ }^{30}$ but they used the pedicled saphenous perforator flap in the distal third leg.

This is the first clinical series on the SAPP flaps. To prevent compromise of the blood supply of the flap and subsequent flap necrosis, minimization of tension at all steps, avoiding acute twists and kinks of perforator pedicle with enough periperforator dissection that allows gracious turn of the pedicle, and diligent handling of the flap right from mobilization to soft tissue closure are the key. The donorsite morbidity associated with the flap procedure is generally minimal. Stiffness of the knee joint may be an issue after reconstruction and subsequent immobilization. While soft tissue healing remains the initial priority, it is judicious to begin mobilization of the knee after 2 weeks. This postoperative protocol explains the good result in our study. The limitation of this study is its small sample size. But the cogency of this study is the clinical establishment of the biogeometry of SAPP flaps and their dependability and reliability in the reconstruction of perigenual soft tissue defects.

\section{Video 1}

Video showing normal gait of case 1 . Online content including video sequences viewable at: www. thieme-connect.com/products/ ejournals/html/10.1055/ s-0039-3400354.

\section{Conclusion}

The SAPP flap is a viable option for the reconstruction of soft tissue defects around the knee joint. Conceivably, it is a reliable flap with consistent anatomy and potentially acceptable donor site. The SAPP flap is a new addendum for the reconstruction of perigenual soft tissue defects.

\section{Informed Consent}

The authors certify that they have obtained all appropriate patient consent forms. In the form, the patients have given their consent for their images and other clinical information to be reported in the journal. The patients understand that their names and initials will not be published, and due efforts will be made to conceal their identity.

\section{Conflict of Interests}

None. 


\section{References}

1 Wei FC, Mardini S. Free-style free flaps. Plast Reconstr Surg 2004;114(4):910-916

2 Mardini S, Tsai FC, Wei FC. The thigh as a model for free style free flaps. Clin Plast Surg 2003;30(3):473-480

3 Wallace CG, Kao HK, Jeng SF, Wei FC. Free-style flaps: a further step forward for perforator flap surgery. Plast Reconstr Surg 2009;124(6, Suppl):e419-e426

4 Eom JS, Hong JP. Lower back defect coverage using a free-style gluteal perforator flap. Ann Plast Surg 2011;67(5):516-519

5 Eom JS, Sun SH, Hong JP. Use of the upper medial thigh perforator flap (gracilis perforator flap) for lower extremity reconstruction. Plast Reconstr Surg 2011;127(2):731-737

6 Acland RD, Schusterman M, Godina M, Eder E, Taylor GI, Carlisle I. The saphenous neurovascular free flap. Plast Reconstr Surg 1981;67:763-774

7 Koshima I, Endou T, Soeda S, Yamasaki M. The free or pedicled saphenous flap. Ann Plast Surg 1988;21(4):369-374

8 Karamürsel $\mathrm{S}$, Celebioğlu S. Use of the medial side of the knee skin as a free flap: saphenous flap. Plast Reconstr Surg 2006;117(4):1308-1314

9 Kansal S, Goil P, Agarwal V, et al. Reverse pedicle-based greater saphenous neuro-veno-fasciocutaneous flap for reconstruction of lower leg and foot. Eur J Orthop Surg Traumatol 2014; 24(1):67-72

10 Bertelli JA. The saphenous postero-medial cutaneous island thigh flap and the saphenous supero-medial cutaneous island leg flap (25.91) Surg Radiol Anat 1992;14(2):187-189

11 Torii S, Hayashi Y, Hasegawa M, Sugiura S. Reverse flow saphenous island flap in the patient with below-knee amputation. Br J Plast Surg 1989;42(5):517-520

12 Breidenbach WC, Terzis JK. The blood supply of vascularized nerve grafts. J Reconstr Microsurg 1986;3(1):43-58

13 Gocmen-Mas N, Aksu F, Edizer M, Magden O, Tayfur V, Seyhan T. The arterial anatomy of the saphenous flap: a cadaveric study. Folia Morphol (WarsZ) 2012;71(1):10-14

14 Li Z, Ding Z, Wang P, Xie Y, Zeng B; Li Z1. [Applied anatomy study and clinical application of great saphenous veno-saphenous neurocutaneous vascular flap]. Zhongguo Xiu Fu Chong Jian Wai Ke Za Zhi 2006;20(3):259-263

15 Sananpanich K, Atthakomol P, Luevitoonvechkij S, Kraisarin J. Anatomical variations of the saphenous and descending genicular artery perforators: cadaveric study and clinical implications for vascular flaps. Plast Reconstr Surg 2013;131 (3):363e-372e
16 Cormack GC, Lamberty GH. The Arterial Anatomy of Skin Flaps 2nd ed New York, NY: Churchill Livingstone; 1994:428-430

17 Kimura N, Satoh K, Hosaka Y. Microdissected thin perforator flaps: 46 cases. Plast Reconstr Surg 2003;112(7):1875-1885

18 Behan F, Sizeland A, Porcedu S, Somia N, Wilson J. Keystone island flap: an alternative reconstructive option to free flaps in irradiated tissue. ANZ J Surg 2006;76(5):407-413

19 Rubino C, Ramakrishnan V, Figus A, Bulla A, Coscia V, Cavazzuti MA. Flap size/flow rate relationship in perforator flaps and its importance in DIEAP flap drainage. J Plast Reconstr Aesthet Surg 2009;62(12):1666-1670

20 Balakrishnan TM, Ramkumar J, Jaganmohan J. Ad hoc posterior tibial vessels perforator propeller flaps for the reconstruction of lower third leg soft- tissue defects. Indian J Plast Surg 2017;50(3):281-287

21 Vasconez LO, Bostwick J III. McCraw J. Coverage of exposed bone by muscle transposition and skin grafting. Plast Reconstr Surg 1974;53(5):526-530

22 McCraw JB. Selection of alternative local flaps in the leg and foot. Clin Plast Surg 1979;6(2):227-246

23 Mathes SJ, Nahai F, Clinical Applications for Muscle and Musculocutaneous Flaps St Louis, MO CV Mosby; 1982

24 Meller I, Ariche A, Sagi A. The role of the gastrocnemius muscle flap in limb-sparing surgery for bone sarcomas of the distal femur: a proposed classification of muscle transfers. Plast Reconstr Surg 1997;99(3):751-756

25 Arnold PG, Mixter RC. Making the most of the gastrocnemius muscles. Plast Reconstr Surg 1983;72(1):38-48

26 Tetreault MW, Della Valle CJ, Hellman MD, Wysocki RW. Medial gastrocnemius flap in the course of treatment for an infection at the site of a total knee arthroplasty. JBJS Essential Surg Tech 2017;7(2):e14

27 Misra A, Niranjan NS. Fasciocutaneous flaps based on fascial feeder and perforator vessels for defects in the patellar and peripatellar regions. Plast Reconstr Surg 2005;115 (6):1625-1632

28 Akhtar MS, Khan AH, Khurram MF, Ahmad I. Inferiorly based thigh flap for reconstruction of defects around the knee joint. Indian J Plast Surg 2014;47(2):221-226

29 Blondeel PN, Morris SF, Hallock GG, Neligan PC. Perforator Flaps: Anatomy, Technique, \& Clinical Applications. 2nd ed. St. Louis, MO: Quality Medical Publishing; 2013

30 Winkel R, Tajsic N, Husum H, Schlageter M, Hanebuth G, Hoffmann R. Saphenous perforator flap [in German]. Oper Orthop Traumatol 2013;25(2):152-161 